\title{
PSICANÁLISE E EDUCAÇÃO, PONTOS DE REFERÊNCIA ${ }^{1}$
}

Jean-Claude Filloux

\section{FREUD E SEU TEMPO}

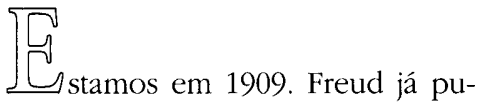
blicou a Interpretação dos sonbos [1900], a Psicopatologia da vida quotidiana [1901], os Três ensaios sobre a sexualidade [1905]. E já se preocupa com a "psicanálise aplicada": um texto sobre $A$ psicanálise e o estabelecimento dos fatos em matéria judiciária, em 1906; um outro, em 1908, sobre A criaçâo literária e o sonbo despertado. Nesse ano, um de seus primeiros discípulos, Sandor Ferenczi pronunciou em Salzburgo uma conferência sobre o tema "Psicanálise e pedagogia", na qual ele questiona, em nome da psicanálise, o caráter repressivo da educação da época e vê na pedagogia um "caldo de cultura das neuroses mais diversas", que negligencia a real psicologia do homem", cultiva o recalque das emoções e leva a uma "cegueira introspectiva" 2 . No ano seguinte, um pastor pedagogo, apaixonado por psicanálise, Oscar Pfister, envia a Freud dois textos que evocam o projeto de uma pedagogia que levava em consideração as descobertas da psicanálise: um intitulase Idéia delirante e suicida dos estudantes, o outro Cuidado psicanalítico das almas e pedagogia moral. Freud the responde, em março de 1909, que ele adere a um projeto que se inscreve assim na possibilidade de estender a psicanálise a outras disciplinas, entre as quais a pedagogia. Sabe-se que é o início de toda uma correspondência entre os dois homens ${ }^{3}$. Quando em 1913, Pfister escreve todo um livro sobre $O$ Método psicanalítico, que visa introduzir a psicanálise em seu programa de ensino aos educadores e pastores, Freud redige um Prefácio em que se encontram estas palavras: "Possa o uso da psicanálise a serviço da educação trazer a realização das esperanças que educadores e médicos põem nela! Um livro como este de Pfister, que se propõe dar a conhecer a psicanálise aos educadores, poderá então contar com a gratidão das gerações futuras"4 . Ulteriormente, Pfister publicará sob o título a Psicanálise a serviço dos educadores 
(1921) várias conferências e Freud não deixará de saudar, em 1926, aquele que "inaugurou" a aplicação da psicanálise à pedagogia em uma carta que lhe envia, - acrescentando aliás que está "muito feliz" porque sua filha Anna "começa a realizar algo nesse campo".

Ainda há outros, nesse período, que participam desta "inauguração". Entre eles, Siegfrid Bernfeld, que publica em 1925 um panfleto (sempre atual por certos enfoques) intitulado Sisifo ou os limites da educação, que contém especialmente páginas muito fortes sobre o "amor paradoxal" pedido aos pedagogos... Também August Aichhorn, que escreve um livro, Juventude abandonada, no mesmo ano, com um prefácio de Freud que diz: "De todos os usos da psicanálise, nenhum encontrou tanto interesse, despertou tantas esperanças... quanto sua aplicação à teoria e à prática da educação infantil". Convém acrescentar que um antigo professor, Hans Zulliger, que se tornou analista de crianças e que havia escrito em 1921 uma obra sobre a Psicanálise na escola, publicará em 1928 um texto sobre "A psicanálise e as novas escolas" cujo interesse reside em demonstrar como os chamados novos métodos podem ser vivificados pela referência psicanalítica. Charles Baudoin, em 1931, escreve, como analista, um dos clássicos da educação psicanalítica, a Alma infantil e a psicanálise

Nesse meio tempo, a Zeitschrift fur psychoanalytische pâdogogik (Revista de pedagogia psicanalítica) deslanchou. Ela durará de 1926 a 1937. Freud havia cumprimentado os artesãos por sua aparição, Henrich Meng e Ernst Schneider, num exemplar de promoção nestes termos : "Os senhores obrigarão por esta criação um grande número de pessoas ao reconhecimento". Pode-se dizer que durante todo esse período a idéia de uma aplicação da psicanálise à educação (ou à pedagogia) percorre seu caminho, mesmo se termos como "pédanalyse", usado por Pfister, são logo abandonados. Em 1933 Freud redige o texto mais completo (e o mais conhecido) sobre as relações entre psicanálise e educação, na famosa " $6^{\mathrm{a}}$ conferência" das Novas conferências de psicanálise ${ }^{5}$, onde se pode ler: "a aplicação da psicanálise à pedagogia, à educação da geração seguinte é um tema especialmente importante de tudo a que se refere à psicanálise".

Freud parece ter citado essa importância de maneira contínua desde 1909. Mas, como considerava ele o próprio processo desta "aplicação"?

Entre 1909 e 1912, a educação é vista como um fator de vocação virtual ou realmente patogênica, na medida em que a repressão social das pulsões é fator de neuroses. Mas ela pode se tornar uma incitação, um auxílio para o domínio do princípio do prazer através da adaptação à realidade e à sublimação. Ao mesmo tempo, Freud acentua o aspecto educativo do processo terapêutico, sendo a cura uma espécie de educação tardia, de pós-educação.

Em 1913, educação e terapia são concebidas como se completando, segundo o indica o Prefácio ao livro de Pfister. A edu- 
cação deve ser profilática, ter por finalidade impedir a formação da neurose, a psicoterapia corrigindo uma evolução mórbida por meio de sua ação reeducativa. Uma orientação psicanalítica da educação deveria possibilitar em larga medida a não formação de neuroses. Lê-se num texto de 1913, publicado na revista italiana Scientia, sobre o tema do Interesse da psicanálise ${ }^{6}$ : "Quando os educadores se houverem familiarizado com os resultados da psicanálise, acharão mais fácil reconciliar-se com certas fases do desenvolvimento infantil e não correrão o risco de exagerar moções pulsionais socialmente não utilizáveis ou perversas na criança... Nossas melhores virtudes nasceram como formações reacionais e sublimações sobre o humus de nossas piores disposições. A educação deveria evitar cuidadosamente fechar essas fontes de forças fecundas e limitar-se a favorecer os processos pelos quais essas energias são conduzidas para o bom caminho. É nas mãos de uma educação psicanaliticamente esclarecida que repousa o que podemos esperar de uma profilaxia individual das neuroses". A chegada de uma nova geração de homens seria doravante possível? Otimismo da época, disseram.

De qualquer modo, tal "otimismo" não é mais encontrado no Prefácio de 1925 ao livro de Aichhorn 6 (bis). De um lado, Freud complicou seu esquema de formação das neuroses e além disso a educação, e mais precisamente a pedagogia, não podem ser concebidas apenas sob o aspecto de uma profilaxia. O trabalho educativo é um trabalho sui generis, que não poderia ser confundido com a intervenção psicanalítica, nem substituído por ela. Aparece então a noção de um educador, analisado ou com informação psicanalítica, que não visa uma "profilaxia individual", mas a elaboração de um processo educativo que torna possível uma "educação voltada para a realidade".

O texto da citada " 6 a Conferência" em 1933 caminha no mesmo sentido. Após evocar os problemas surgidos com as psicanálises infantis, Freud procura determinar como a educação pode "realizar o máximo e prejudicar ao mínimo". Tarefas difíceis cabem ao educador no caminho que ele deve encontrar "entre Scylla do deixar fazer e o Charybde da frustração" para "reconhecer a natureza particular da constituição da criança, adivinhar por fracos índices o que se desenvolve em sua vida psíquica inacabada, lhe dispensar a justa medida de amor e, no entanto, conservar uma parte eficaz de autoridade". Nessas condições, não seria uma formação psicanalítica a única preparação apropriada à profissão de educador? "A análise dos mestres e educadores parece uma medida profilática mais eficaz que a das próprias crianças"...

Tal texto continua, no entanto, suficientemente ambíguo para ter dado lugar a numerosas exegeses 7 . É claro que Freud, quando evoca a aplicação da psicanálise ao campo da educação, designa uma educação psicanalítica, isto é, uma educação atualizada no quadro escolar ou familiar que se inspira nos trabalhos da psicanálise. Todavia o "como" desta atualização quase não é explicitado, exceto a sugestão de uma análise dos mestres. Por isso Freud é prudente sobre as possibilidades reais de um tal projeto (retomado nessa época por certos autores da Revista de pedagogia psicanalitica, mas considerado impossível por outros, e até pelo próprio Freud). Por outro lado, uma questão de fundo transparece nesse texto, que concerne desta vez o próprio status do conceito (ou da própria operação) de aplicação. Se a "aplicação", como no texto de 1913, é de um indiscutível 
"interesse" e indicada como caminhando sozinha, objeções radicais são apontadas: a tarefa pedida aos educadores corre o risco de ser "insolúvel", ela é difícil de realizar se não for "idealmente" (tarefa utópica?); e ainda, Freud diz fazer "total abstração do fato que se recusará à psicanálise qualquer influência sobre a educação, se ela declarar abertamente intenções que são inconciliáveis com a ordem social existente". Poderia haver, entre a psicanálise, que tem seus próprios objetivos e sua própria "verdade", e a educação, cuja função é a adaptação a uma ordem, disparidade em algum ponto? De modo geral, poderia a "aplicação" estar marcada com o selo da irredutibilidade, conduziria ela a um impasse?

De qualquer forma, os que escrevem, entre 1926 e 1932, na Revista de pedagogia psicanalítica, não fazem esse tipo de perguntas e, se eles têm respostas, provam de certa forma o movimento caminhando. A "pedagogia psicanalítica" é pensada como constituindo um ramo autônomo da psicanálise, trate-se de psicanalistas, como Fritz Redl ou Heinrich Meng, ou de pedagogos, como Oscar Pfister ou Hans Zulliger. Se a idéia geral é de usar conhecimentos" adquiridos pela (ou por uma) psicanálise para criar novos métodos educativos, a maneira de os "utilizar" revela caminhos diferentes, dentre os quais alguns podem fazer pensar no prólogo de uma verdadeira viragem na concepção do processo de "aplicação".

De fato, ao lado de textos que se referem a problemas surgidos na análise de crianças, a sexualidade infantil e sua educação, a terapia de distúrbios infantis diversos, que formam uma série de experiências ao nível da família, jardins da infância, escolas, outros textos vão mais longe e encetam uma exploração analítica da relação do educador com seu projeto educativo. Num primeiro tempo, trata-se principalmente de teorizar a idéia mesma de um "educador psicanalítico", munido de meios que lhe permitem tornar-se mais sensivel à realidade educativa, inventar técnicas de "ajuda educativa". Mas, num segundo tempo, é a própria personalidade do educador (do pedagogo) que se torna objeto de estudo. Num artigo de 1936, Ruth Weiss nota que a evolução do trabalho dos colaboradores da Revista vai de um interesse pela psicologia do aluno a um interesse crescente pela psicologia do pedagogo. "Como nos tornamos pedagogos?" Tal é por exemplo a questão à qual a psicanálise pode ajudar a responder, e ela cita a este propósito textos de Willy Kuendig, Ernst Schneider, que podem inscrever-se sob a rubrica "Do inconsciente do pedagogo". Três textos da Revista, que estudam a relação do professor e do aluno sob o ângulo da transferência podem ser considerados um verdadeiro prólogo à concepção dos conhecimentos analíticos como podendo servir a uma elucidação da relação educativa. Edmund Fisher, em 1929, diz em "O sexo e a transferência" que a transferência representa um papel decisivo na relação professor-aluno e alerta para o estabelecimento ou a aceitação na escola de uma transferência positiva do aluno sobre o mestre, particularmente quando se trata de professores masculinos em classes de meninas. Em resposta, Zulliger ("L' épouvante du lien" - "O pavor do vínculo", 1930) tenta aclarar a noção de "vínculo" tal como ela resulta da transferência que Fisher e outros teriam mal interpretado ${ }^{8}$. De seu lado, Wilhelm Hoffman ("O ódio do professor"- "La haine de l'enseignement", 1929) evoca o problema do professor que se vê objeto de ódio e de sua atitude em relação à sua própria contratransferência.

É interessante notar que estes tex- 
tos foram publicados antes da " 6 a Conferência" de Freud e estão de certo modo à frente dos desenvolvimentos ulteriores de uma psicanálise aplicada à educação que só podem ser lidos nas entrelinhas em Freud 9 . Eles são ao mesmo tempo significativos de uma tendência para distinguir, melhor que o fazia Freud, a questão da educação (que implica educação familiar e educação escolar) da questão pedagógica, no quadro específico da escola, das relações mestre-aluno que se instituem e da personalidade do pedagogo.

\section{APÓS FREUD, PSICANÁLISE E EDUCAÇÃO HOJE}

Se se deixam de lado os problemas surgidos na análise de crianças e adolescentes, que são de certo modo problemas de ordem estritamente analítica, a problemática da "aplicação" ou do "uso" da psicanálise no campo da escola, pode ser assim esquematizado:

- Trata-se por ventura de estender a prática analítica (a cura) a uma prática educativa (ensinar, educar)? Ou antes de "fertilizar" esta última por um Saber ( o saber analítico) originário da cura. Nos dois casos, pode-se talvez falar; na terminologia da Revista, de "analista pedagogo". Mas no primeiro caso surge a questão crucial da diferença, provavelmente incontornável, do projeto analítico e do projeto educativo ao nível da prática. No segundo, o risco é de, ao querer "melhorar" do lugar de um Saber (analítico), legiferar e dar à análise uma posição normativa que lhe é por direito estranha.

- No entanto pode-se colocar, na linha do desenvolvimento já esboçado pela Revista indicado acima, que a análise (saber ou prática) é antes de tudo interpretação, isto é, leitura e decodificação. Tratar-se-á então -seja de "uti- lizar" o Saber analítico (teoria corpus) para uma exploração do campo da educação redundando na produção de um conjunto de novos conhecimentos sobre o citado campo, -seja de tomar em face deste campo, enquanto pesquisador "analista", uma atitude interpretativa redundando também num saber sobre em que ponto está a educação.

Nestes dois últimos decênios, estes dois grandes tipos de aplicação (inspiração imediata de uma prática, leitura em referência a um saber) dividem-se em pesquisas e publicações, embora o segundo, mais recente, seja provavelmente o mais heurístico.

1 - O que se pode chamar de "tradição" da pedagogia psicanalítica toma lugar na corrente geral da psico-pedagogia. Aos pedagogos (professores, educadores) se exigiria menos uma formação psicanalítica - como nos primeiros tempos- que uma consciência dos aportes da psicanálise no desenvolvimento da criança, do adolescente, através de uma formação que pode tomar várias formas. Não foi por acaso que a partir da instalação, desde 1945, de uma pedagogia curativa, no Centro Claude Bernard, Georges Mauco, em 1967, vê na psicanálise um auxílio, seja para uma psicoterapia de crianças e adolescentes, seja do lado do professor, para uma melhor "compreensão" do aluno. Mauco centra efetivamente seu livro, mais sobre esta compreensão que sobre os cuidados; ele desenvolve também, numa perspectiva que se aproxima mais do que chamamos o "segundo tipo" de aplicação, o problema da identificação com o mestre e da transferência. $10^{5}$.

A pedagogia psicanalítica é evocada na Alemanha na mesma época (1968) por uma obra de Walter Schraml, Initiation à la pédagogie psychanalytique, 11 que retoma textos anteriores de Meng e de Zulliger sobre a sublimação e elabora uma tipologia "psi- 
canalítica" do educador, prelúdio a preceitos relativos a sua "higiene mental". Mas é principalmente ao nível da emergência da pedagogia institucional que se desenvolve o que se pode chamar de infiltração da psicanálise na teoria pedagógica. ${ }^{12}$ A pedagogia proposta por Aïda Vasquez e Fernand Oury leva deliberadamente em conta "a existência do inconsciente", assim como "um feixe de noções teóricas, como o fantasma, a transferência, o super-eu, e quer particularmente "utilizar, no âmbito escolar, a noção de identificação" para "introduzir psicanálise na aula". Esta infiltração será também encontrada um pouco mais tarde no trabalho pedagógico, para dizer a verdade, muitas vezes mais reeducativo que educativo, evocado nos textos de Xavier Audouard, o qual situa sua reflexão e sua prática a partir da condição de analista e não de pedagogo. 13 Audouard propõe um novo modelo de função educativa fundado sobre a noção de escuta educativa à imagem da de escuta analítica e chega até a imaginar um termo para designar esse educador analista que não imporia, mas faria "surgir ou revelar o sentido", o de "edutor". Levado a este extremo,o tema da pedagogia psicanalítica se radicaliza e faz mais que nunca a pergunta da clivagem da posição de analista e de pedagogo. Em sua obra l'illusion psychanalytique en éducation 14, Jean-Pierre Bigeault $\mathrm{e}$ Gilbert Terrier denunciam como ilusória a idéia de uma pedagogia dita analítica em que a psicanálise não seria pervertida. $\mathrm{O}$ "modelo da cura" é insustentável, com o risco de se tornar mistificação: o "saber" analítico usado pelo pedagogo só pode ser um saber morto uma vez que fora de seu uso na cura... Seria então condenável qualquer pedagogia "inspirada" na psicanálise?

A questão é a do sentido próprio desta "inspiração", e do que se coloca sob o conceito do Saber analítico. A maiúscula que pusemos intencionalmente no termo não deveria implicar a concepção monolítica de um "corpus teórico", que seria uma espécie de paradigma fechado, com um consenso fixo. Por outro lado, o que interessa à educação, é também um saber que, por ser analítico, nem por isso é menos obtido tanto pela experiência de psicanálises de crianças ou de reeducação (por exemplo) como pela referência ao dito "corpus" analítico. Se houver saber, ou "Saber", pode-se designar por este termo, ou o que, do corpus geral, interessa mais especialmente à educação: teoria da sexualidade infantil, o Édipo, as identificaçôes, etc..; - ou o que pode ser produzido pela pesquisa no âmbito específico do campo educativo.

2 - O que chamamos o "segundo tipo" de aplicação quer precisamente constituir, por um método interpretativo, um "saber analítico sobre" que representa o resultado de um uso da análise, mas fora do campo de uma praxis. Falaremos doravante mais de uso que de aplicação; mais de objetivo de exploração que de pedagogia no sentido de uma ação "inspirada".

Tal uso pode tomar a forma de análise de discurso; o discurso escrito de teóricos da pedagogia, o discurso obtido por encon- 
tros de professores, alunos e outros parceiros do jogo educativo; mas também o que se chama de "discurso institucional", que está ligado ao coletivo. Ele pode ainda tomar a forma de análise, observações, - observações de aulas, de práticas pedagógicas. Material a decifrar, para ler o que, do pedagógico, está ligado ao inconsciente.

Evocaremos apenas alguns temas publicados nesses últimos quinze anos. Referem-se à situação do aluno em sua relação com o mestre e com o saber, a relação quem ensina-quem é ensinado, o grupo.

Sendo a escola lugar -institucionalde transmissão de saberes e apoiandose sobre uma atividade intelectual do aluno, temos que nos interrogar, como analistas, sobre o que fundamenta o desejo de saber do aluno, o funcionamento e o destino das pulsões da libido ligadas a esse desejo, a maneira pela qual se opera sua sublimação. Aparecerá, por exemplo, que a atividade intelectual depende ao mesmo tempo da sublimação e de um trabalho de idealização e de identificação com o professor, de tal maneira que o professor representa um papel no destino do desejo de saber do aluno. Captura deste desejo? É o que descreve Octave Mannoni num texto intitulado "Psicanálise $\mathrm{e}$ ensinamento". Após a constatação de que a instituição escolar é feita para garantir ao professor o papel de "mestre do saber", demonstra-se como "o desejo de saber do aluno é paradoxalmente deslocado pelo desejo ambíguo do mestre de que o aluno saiba": assim "seu desejo de saber lhe é raptado" 15. $\mathrm{Na}$ mesma perspectiva, Claude Rabant, a partir de uma leitura "analítica" do Emile e de um certo número de textos de teóricos dos métodos ativos, tais como Claparède, Ferrières, analisa o que, em qualquer pedagogia, é da ordem da "astúcia" e tem por objeto substituir o desejo de saber do aluno pelo desejo de um outro saber ${ }^{16}$. Nessa perspectiva, perguntar-nos-emos, com os participantes de um Congresso de 1973, qual é a relação do desejo do professor com a constituição do ideal do eu da criança: mesmo que o professor resista a seu desejo de que a criança identifique suas posições com a sua, não estaria ele determinado pela própria situação educativa a ocupar o lugar do ideal do eu (moi) da criança? ${ }^{17}$ Não implicaria para outros a posição de representante da função do saber, assim como em relação à função de controle da libido do sistema escolar, nessas condições, um recalque do desejo de saber? Problema da identificação e da idealização, de seus vínculos com o processo de sublimação 18 .

Por conseguinte, a questão é de passar da análise da posição do aluno a do professor, em sua relação de educação. Assim Marie-Claude Baïetto explora, no Désir d'enseigner, o desejo de amor (amar e ser amado), uma certa paixão por influência, as transferências e contra-transferências ligadas à situação de ensino; isto na linha das intuições de Daniel Hameline, analisando, principalmente no $D u$ savoir et des bommes, os móveis da "intenção de instruir" as "ilusões" em jogo, não menos que os "riscos da profissão" 19 , e em continuidade com o trabalho elaborado por Janine Filloux sob o título $D u$ contrat pédagogique. Esta obra tem por objetivo a análise da dinâmica inconsciente da relação pedagógica e dos fantasmas subjacentes a partir de conversas não-diretivas de professores e alunos. Janine Filloux faz a hipótese de um "contrato de posição" de natureza paradoxal e imaginária entre os parceiros, no qual, sob as aparências de um contrato racional, pesam os elementos afetivos do amor e do ódio. Assim fica aberta uma interrogação sobre a irra- 
cionalidade da ordem escolar: ordem consumatória ou ordem sublimatória? 20. Utilizando uma metodologia análoga as de Janine Filloux e Marie-Claude Baietto, Claude Pujade-Renaud dedicou-se por sua vez a aprofundar o discurso dos professores e dos alunos sobre o corpo, procurando em que ponto está a sexualização da relação pedagógica e da teatralização do corpo, com o duplo surgimento de um "corpo simbólico", o jogo da homossexualidade e da heterossexualidade fantas$\operatorname{madas}^{21}$.

Fantasmas individuais e também fantasmas de grupo. Os estudos de Didier Anzieu e René Kaes, a partir de um "trabalho psicanalítico" nos grupos, contribuiram para uma abordagem psicanalítica do "aparelho psíquico grupal", capaz de trazer uma melhor compreensão do funcionamento do grupoaula, embora estes autores se dediquem a decifrar o fantasmático da formação e o desejo de formar em grupos de formação e não no grupo escolar 22 .

O maior risco do uso da psicanálise como instrumento de interpretação e conhecimento do "campo" dito educativo, ou pedagógico, seria fazer dele uma espécie de grade de leitura exterior, modelada sobre o material obtido, o saber psicanalítico funcionando consequentemente como fechamento, risco que outros nem sempre souberam evitar. Mireille Cifali aponta bem o problema, quando mostra que, na relação do sujeito em pesquisa e das práticas e especialmente em práticas discursivas, que são objeto da pesquisa, trata-se de que o sujeito ( na perspectiva de aplicação da psicanálise) esteja em posição... de analista.

De um modo geral pode-se colocar a questão do "interesse" da aplicação da psicanálise para o professor, até mesmo ao nível de uma "teoria" do ensino. Se se tratar da aplicação imedi- ata de um "saber fazer" psicanalítico no quadro de uma "pedagogia psicanalítica", é a relação pedagógica, no sentido de uma metodologia da relação, que está em jogo. Mas o que é feito desse "interesse" no plano da leitura do campo pedagógico, que acabamos de evocar, que se trate do uso intelectual do "saber analítico" ou da tomada de uma posição de analista?

Parece que, a priori, qualquer aporte de conhecimento originário de uma pesquisa no campo pedagógico é suscetível de uma "consideração" pelos atores com uma virtude formativa. No entanto é menosprezar as resistências nascidas da própria natureza dos "conhecimentos" produzidos, cuja transmissão só pode questionar o professor. É por exemplo interessante notar que as hipóteses saídas da sociologia da educação são muito mais facilmente recebidas que as saídas da psicanálise: Freud já falava de um efeito de subversão inerente à extensão da psicanálise à educação. .

Viu-se que Jean-Pierre Bigeault e Gilbert Terrier falam de uma "ilusão psicanalítica" em educação 23. Ao contrário, outros como Daniel Hameline, vêem na análise a iluminação que mais nos ensina sobre a paixão de instruir, a relação com o saber, os fracassos da educação. Apenas retomaremos, in fine, estas linhas do relatório da Comissão "Psicanálise e educação" do Congresso de 1973, referente à posição do educador em relação às pesquisas de tipo psicanalítico: "há uma possibilidade de que a leitura do campo pedagógico e educativo e a leitura dele mesmo nesse campo possa interrogá-lo sobre sua prática e colocá-lo ele mesmo em posição de criar". 24 


\section{NOTAS}

1 Este texto foi publicado originalmente em Setembro de 1986, sob o título "Psychanalyse et éducation: repères" na Revista ETUDES PSYCHOTHERAPIQUES, Toulouse, Privat, $\mathrm{n} 65$.

2 S. Ferenczi, "Psychanalyse et pédagogie", Oeuvres complètes, I, Payot. Citado por M. Cifali e J. Moll, in Pédagogie et psychanalyse, Dunod, 1985.

3 Correspondance de Sigmund Freud avec le pasteur Pfister, Paris: Gallimard, 1967.

${ }^{4}$ Citado por M. Cifali in Freud pédagogue? Paris: Inter-éditions, 1982.

5 De fato, trata-se da 34a. conferência, na numeração de Freud, retomada na recente tradução das Novas conferências (Nouvelles conférences d'introduction à la psychanalyse) publicada na coleção "Connaissance de l'Ïnconscient", pela Gallimard. As citaçôes que fazemos são tiradas desta última traduçào, mesmo quando conservamos o título habitual (" 6 a conferência").

${ }^{6}$ Capítulo : "O interesse do ponto de vista pedagógico", Ed. Retz.

6 (bis) Freud evoca a idéia de uma "educação visando a realidade" em l'Avenir d'une illusion (p. 70). O contexto é uma interrogação sobre a possibilidade de um excesso pelos humanos do narcisismo, do infantilismo e das "Ilusōes" que a eles estão ligadas no nosso atual estado de "civilização", "O homem não pode continuar eternamente uma criança": uma educação não fundamentada sobre ilusões ou capaz de as colocar em xeque deveria garantir, segundo o comentário de Catherine Millot em Freud anti-pédagogue, (Bibl. Ornicar, 1979, p. 107, "a supremacia da razão sobre as forças do instinto em detrimento do recalque". De seu lado, Mireille Cifali vê nisso, "o desejo de que a educação perca o imaginário sobre o qual ela funciona”. (o.cit. p. 124)

7 Citemos, nos últimos anos, os comentários de: Geneviève Lombard. "Sobre a noção de psicanálise aplicada, principalmente aplicada à educaçâo", in Apport des sciences fondamentales aux sciences de l'éducation, Epi, 1974, t. I, p. 412-419; Janine Filloux, "Eléments de réflexion sur l'application des données de la théorie psychanalytique au champ de la pratique enseignante", in Revue française de pédagogie, n 54, 1981, p. 32-39 ; Mireille Cifali, capítulo 3 , in o.c. Freud pédagogue?

8 Contrariamente ao que afirma Fisher, diz Zullinger, o caso das meninas parece "ser de longe o mais favorável, contanto que a afeição seja por um professor como objeto de amor heterosexual... Se não for o caso de meninas neuróticas, apaixonar-se pelo professor marca apenas uma transição no desenvolvimento, isto é, a passagem do amor infantil ao amor completo do adulto". Em compensaçào, a afeiçào homossexual por uma professora pode tornar a menina incapaz para sempre de ter ligaçôes heterossexuais.

${ }^{9}$ Mireille Cifali nota que se encontram em Freud muitos textos focalizando concretamente a relação psicanálise-educação de forma diferente que na ótica de uma profilaxia educativa, mas sob o aspecto de uma análise do próprio processo pedagógico : presença de efeitos transferenciais na relação pedagógica, ligação entre as pulsões epistêmicas e as pulsôes sexuais, relações entre homossexualidade e pedagogia, etc...(Capítulo "Incursions freudiennes", in Freud pédagogue?). 
${ }^{10}$ G. Mauco criou em 1945 o Centro psico-pedagógico Claude Bernard, em companhia do Dr. Berge, de Françoise Dolto e de Juliette FavezBoutonnier.Cf. Psychanalyse et éducation, 1967, Aubier-Montaigne.

11 Walter Schraml, Initiation à la pédagogie psychanalytique, 1968, Salvator.

12 Aïda Vasquez e Fernand Oury, Vers une pédagogie institutionnelle, 1967, Maspero. Os autores se admiram de que "a obra de Freud que faz da criança o pai do homem, parece ignorada pelos pedagogos" (p. 199). Convém "utilizar noçôes psicanalíticas para esclarecer, explicar o que se passa numa aula...", mas "qualquer tentativa de introdução da psicanálise na aula requer uma formaçào mínima dos mestres" (p. 233, p. 238).

13 Xavier Audouard, l'Idée psychanalytique dans une maison d'enfants, 1970, Epi.

14 Jean-Pierre Bigeault e Gilbert Terriuer, l'Illusion psychanalytique en éducation, 1978, P.U.F.

15 Octave Mannoni, "Psychanalyse et enseigement", Revue de Psychologie et Sciences de l'éducation, 1970. Retomado in Un commencement qui ne finit pas, Seuil.

16 Claude Rabant, "l'illusion pédagogique", in l'Inconscient, 8, 1968.

17 VI Congresso Internacional das Ciências da educação, 1973, Relatório da Comissão "Psicanálise e Educação", in Apport des Sciences fondamentales aux Sciences de l'éducation, t. I, p. 410-411, Epi, 1974.

18 Piera Aulagnier trouxe uma contribuição útil à elaboração desse tipo . de problema de educaçào num artigo intitulado "O desejo de saber em suas relações com a transgressão", in l'Inconscient, 1, 1967. O desejo de um saber sobre o desejo é mostrado "no coração mesmo da relação do sujeito com o conhecimento" - deste sujeito que é confrontado com o próprio desejo do educador.

19 Marie-Claude Baïetto, le Désir d'enseigner, ESF, 1982, Daniel Hameline, Du savoir et des hommes, Gauthier-Villards, 1971; le Domestique et l'affranchi, Ed. Ouvrières, 1977.

20 Janine Filloux, Du contrat pédagogique, le discours inconscient de l'école, Dunod, 1974. Ver também "Clinique et pédagogie" in Revue française de pédagogie, n. 64, 1983 onde, a partir de uma reflexão sobre a prática educativa como encenaçào de uma relação de geração e filiação simbólica, interroga-se a natureza das resistências em jogo e a necessidade de um diálogo entre o "pedagógico" e o "clínico".

21 Claude Pujade-Renaud, le Corps de l'enseignant dans la classe, ESF, 1983; le corps de l'élève dans la classe,ESF, 1984.

22 René Kaes, Didier Anzieu et al., Fantasme et formation, Dunod, 1973 ; Désir de former et formation du savoir, Dunod, 1976.

23 No entanto em Une école pour Oedipe,Privat, 1975, é bem uma pedagogia de referência psicanalítica que é proposta.

24 o.cit., p.411. 